\title{
MiniTeste: uma ferramenta ágil para aplicação de avaliações personalizadas
}

\author{
Rex A. C. Medeiros - ECT/UFRN - rexmedeiros@ect.ufrn.br \\ André Bessa - ECT/UFRN - abessa@ect.ufrn.br
}

Resumo. O uso da tecnologia pode potencializar metodologias que proporcionem uma participação mais ativa dos estudantes. No caso de turmas numerosas, esses recursos tecnológicos tornam-se indispensáveis. Neste artigo, apresentamos a ferramenta MiniTeste para a aplicação e a gestão de avaliações rápidas e individualizadas, em papel ou dispositivo móvel. Discutiremos como suas funcionalidades podem viabilizar, no contexto brasileiro, dinâmicas de avaliação tendo por base testes conceituais curtos e frequentes e a interação entre os estudantes, permitindo a adaptação em tempo real a diferentes cenários de respostas por parte da turma. A ferramenta MiniTeste foi desenvolvida para dar suporte à implantação, em turmas numerosas, da combinação de duas metodologias, a saber, a sala de aula invertida e a instrução por pares, podendo ainda ser usada em vários outros contextos.

Palavras-chave: tecnologia educacional, metodologias ativas, instrução por pares, avaliação, turmas numerosas.

\section{MiniTeste: an agile tool for individualized assessment}

Abstract. Methodologies for active learning can profit from the use of technology. In special contexts, such as those of large classes, the help of technological resources is critical. In this paper, we present the MiniTeste tool for creation, management and application of individualized single-question assessments that can be printed or accessed by mobile devices. We discuss how its features contribute to assessment practices based on the recurrent use of key conceptual questions, allowing for realtime adjustments of the pedagogical strategies according to classroom performance. The software was aimed at supporting peer instruction and flipped classroom methodologies in the Brazilian context, but it can also work on other approaches.

Keywords: educational technology, active learning, peer-instruction, assessment, large classes.

\section{Introdução}

O modelo tradicional de aulas expositivas, tão comum em escolas e universidades brasileiras, possui suas limitações. Uma das mais importantes é não ter o foco no principal agente do processo de ensino-aprendizagem, que é o estudante. Outro problema das aulas expositivas é que, após os minutos iniciais da aula, a concentração dos estudantes cai significativamente (Johnson; Percival, 1976) (Poh et al., 2010). Palestrando diante de mentes dispersas, passa-se a um monólogo onde dúvidas raramente são levantadas, revelando a quase ausência de pensamento crítico. Nos cursos 
de graduação das áreas de Ciências Exatas e de Engenharias, em geral, essa prática metodológica é amplamente empregada.

Nesse contexto, novas metodologias vêm sendo experimentadas com o objetivo de trazer o estudante para o centro de uma arena instigante onde se desenvolvem as discussões que levam ao aprendizado. São as chamadas metodologias ativas. Nelas, cabe ao docente o comando de uma série de ações que proporcionem uma orientação individualizada aos estudantes. Algumas das estratégias metodológicas que possuem essas características são os estudos de caso, os mapas conceituais (Gerab; Trentin, 2015), os debates, as dramatizações, o ensino baseado em projetos (Souza, 2011), em experimentos ou em equipes (Bollela et al, 2014), a instrução por pares (Müller, 2013) e a sala de aula invertida. Não existe uma estratégia ótima a todas as situações. A adoção de uma ou a combinação de estratégias metodológicas depende fundamentalmente do tipo de conteúdo a ser ministrado e das características da turma.

$\mathrm{O}$ desafio de trabalhar com metodologias ativas torna-se ainda maior quando as turmas são numerosas e heterogêneas. Esse é o caso, por exemplo, do Curso de Bacharelado Interdisciplinar em Ciências e Tecnologia (BCT) da Universidade Federal do Rio Grande do Norte (UFRN), que possui uma entrada semestral de 560 estudantes, sendo que $45 \%$ dos ingressantes são oriundos da rede pública de ensino (UFRN, 2016). Para cada componente curricular obrigatório do BCT são ofertadas semestralmente pelo menos quatro turmas de até 140 alunos/turma. Após um estudo prévio sobre metodologias ativas e suas aplicações, docentes responsáveis pelo componente Computação Numérica vêm combinando duas estratégias ativas, a sala de aula invertida e a instrução por pares, e aplicando-as semestralmente em uma das turmas com tamanho entre 70 e 100 estudantes.

A combinação da sala de aula invertida e da instrução por pares já é usada há pelo menos duas décadas com sucesso em cursos de graduação de ciências exatas e de engenharia nas melhores universidades do mundo, a exemplo da Universidade de Harvard e do MIT (Mazur, 1997). Especialmente na instrução por pares, uma das linhas de ação empregada busca manter a atenção e o interesse na discussão por meio de perguntas-chave realizadas durante a aula e que devem ser respondidas rapidamente por cada estudante. As respostas dos alunos são levadas em conta pelo docente para avaliar o grau de compreensão individual e coletivo sobre o tema abordado. Caso o grau de compreensão individual não seja satisfatório para um determinado tema, inicia-se uma discussão em grupo, entre os estudantes, acerca da questão proposta. É uma maneira de socializar as dúvidas, os raciocínios dos estudantes para suscitar, em cada um, a reflexão necessária para se atingir um conhecimento. Argumenta-se que os elementos reflexivos compartilhados pelos pares são potencialmente mais significativos para quem está aprendendo do que aqueles trazidos pelo professor, cujo processo de aprendizado se deu em um contexto distante no tempo e no espaço. Nessa estratégia, a dinâmica da aula vai depender das respostas dos estudantes, ou seja, o plano de aula precisa prever diferentes percursos.

Em geral, a utilização de metodologias ativas não requer o uso de Tecnologias da Informação e Comunicação (TICS). Na instrução por pares, por exemplo, é possível conhecer as respostas dos alunos fazendo com que cada um erga uma placa com a alternativa que achar correta, cabendo ao docente fazer a contagem e mesmo anotar o nome dos alunos com suas respectivas respostas. Originalmente, Mazur (1997) utilizou um pequeno dispositivo físico com botões que denominou clicker. Ao se realizar esse tipo de atividade em turmas numerosas, a utilização de ferramentas de TICS torna-se imprescindível, tanto para agilizar o processo de obtenção das respostas como para se 
obter relatórios de forma rápida e precisa sobre o desempenho coletivo ou mesmo individual de cada estudante.

Com a popularização dos celulares e da Internet, vários aplicativos foram desenvolvidos com o intuito de dar suporte às atividades em sala de aula. Como será mostrado na próxima seção, nenhum aplicativo encontrado no Google Play, na Apple Store e mesmo na Internet, mesmo após uma busca exaustiva, satisfaz os requisitos que consideramos chaves para aplicação com sucesso da estratégia de instrução por pares no ambiente de turmas grandes e levando-se em conta o perfil dos estudantes brasileiros.

Neste artigo apresentamos a ferramenta MiniTeste, desenvolvida com o objetivo de fornecer as funcionalidades necessárias para a preparação, execução e gestão de testes rápidos que viabilizem metodologias baseadas na instrução por pares no contexto brasileiro. A ferramenta foi desenvolvida na Escola de Ciências e Tecnologia da UFRN (ECT/UFRN).

\section{Instrução por pares e ferramentas de TICS}

Para entender a importância que as ferramentas de TICS possuem na instrução por pares, é necessário descrever minimamente essa metodologia. O uso da estratégia de instrução por pares combinada com a sala de aula invertida foi iniciado na universidade de Harvard, nos Estados Unidos, em aulas de Física (Mazur, 1997). A Figura 1 ilustra o fluxograma de uma aula que combina as duas estratégias.

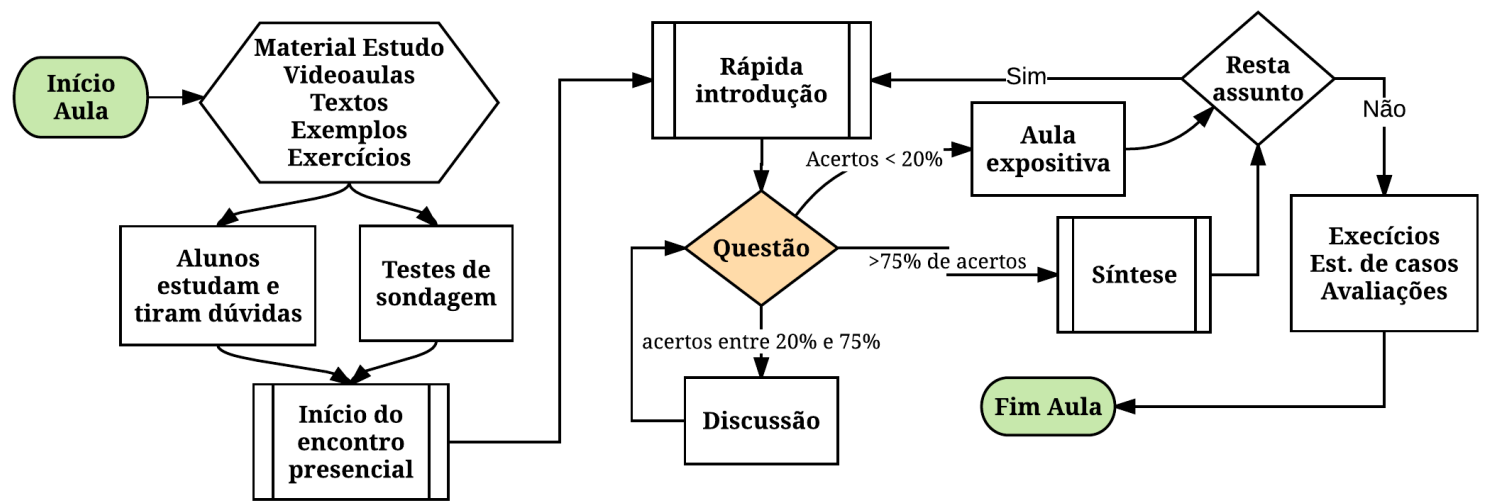

Figura 1 - Diagrama com o fluxograma dos possíveis percursos didáticos em uma abordagem que utiliza a instrução por pares.

Nessa metodologia, os estudantes devem estudar previamente o conteúdo da aula através de videoaulas, leituras orientadas, etc. Durante o encontro presencial, o docente afere a aprendizagem dos estudantes sobre determinado tópico através de questões-chave previamente e cuidadosamente elaboradas. As questões são sempre colocadas após uma contextualização rápida de, no máximo, 5 minutos. A questãochave é inicialmente respondida de forma individual. Caso uma porcentagem alta da turma acerte a questão (p. ex., pelo menos 75\%), o docente considera que o objetivo foi alcançado, realiza uma rápida discussão/síntese e passa para o próximo tópico da aula. Quando a porcentagem de acerto estiver dentro de um patamar estabelecido, inicia-se uma fase de discussão entre os alunos, mediada pelo professor com o auxílio de monitores, quando disponíveis. Assim, os alunos que acertaram a questão e que possuem um maior domínio do conteúdo auxiliam no processo de aprendizagem dos restantes. Ao final da discussão, a mesma questão é colocada para os que erraram e os mesmos têm uma segunda chance de respondê-la. Se por outro lado a taxa de acerto estiver abaixo de um limiar na primeira tentativa (p. ex.: $<20 \%$ ), o docente considera 
não haver massa crítica suficiente para uma discussão frutífera e parte-se para outra abordagem. Portanto, um dos elementos cruciais na aplicação dessa metodologia é a questão-chave. Ela serve como um termômetro para medir o quanto os alunos estudaram previamente e aprenderam os conteúdos.

Quando essa metodologia é usada em aulas sucessivas, fica clara a necessidade de o aluno estudar o conteúdo sempre antes do encontro presencial. Do ponto de vista do aluno e por razões culturais, a simples introdução de uma metodologia nova não garante o engajamento da turma, acostumada com aulas expositivas e a estudar somente às vésperas das avaliações. A nossa experiência ao longo de três semestres mostrou que é necessário existir alguma compensação para que haja adesão da turma à proposta; um relato minucioso da implantação dessa metodologia é objeto de um artigo em preparação. No caso, essa compensação se traduziu em incluir as questões-chave no sistema de avaliação do componente curricular. Em outras palavras, foi preciso que a questão-chave contribuísse de alguma forma para a nota da disciplina. Nesse contexto, a aplicação de avaliações objetivas idênticas é um convite à fraude, pelo fácil compartilhamento dos gabaritos. Assim, dentre os aspectos operacionais levados em conta está o uso de questões individualizadas, ou seja, diferentes, para cada estudante.

Dentre as ferramentas de TICS disponíveis atualmente e que podem ser usadas para a aplicação das questões-chave algumas merecem destaque. O Socrative (http://socrative.com), o iclicker (http://iclicker.com) e o Google Sala de Aula (http://classroom.google.com) permitem que o professor crie questões objetivas simples que os estudantes podem responder através de um aplicativo para celular. O Plickers (https://plickers.com) possui as mesmas funcionalidades mas tem a vantagem de não exigir que os estudantes possuam dispositivos móveis, necessário somente para o professor; como desvantagem, o Plickers só pode ser usado em turmas de, no máximo, 63 alunos, o que não é adequado para a realidade de várias disciplinas de início de graduação após a recente expansão do Ensino Superior. O Piazza (https://piazza.com) é um software de gerenciamento de turmas que também possui, dentre outras, as mesmas funcionalidades do Socrative e do iclicker e necessita que cada estudante possua um dispositivo móvel. No nosso contexto socioeconômico, não é razoável supor que todos os estudantes possuam dispositivos móveis com acesso à Internet.

Outro aspecto essencial é que os softwares disponíveis não foram desenvolvidos objetivando oferecer suporte à metodologia baseada na instrução por pares, onde existe toda uma dinâmica de formação de grupos entre a primeira e a segunda tentativa de resposta. Em suma, não há registros de ferramentas de TICS para aplicação de testes rápidos e que possuam as seguintes características desejadas para o suporte à metodologia em tela: (a) geração de testes individualizados; (b) possibilidade de uso em turmas numerosas sem o requisito de que cada estudante deve dispor de um dispositivo móvel e (c) gerenciamento de diferentes cenários conhecidos apenas durante a avaliação. A ferramenta MiniTeste, desenvolvida ao longo do processo de implantação dessas metodologias na ECT/UFRN, possui essas e outras características e aplicações que serão descritas nas próximas seções.

\section{A ferramenta MiniTeste}

O desenvolvimento de uma nova ferramenta com determinadas especificações deve ser justificado pela ausência de certas funcionalidades nos aplicativos existentes e pela relevância dessas novas funções. Além disso, dentro de um mesmo ambiente de utilização, é importante que aplicativos com finalidades correlatas não tenham sobreposição de funcionalidades e que, na medida do possível, essas aplicações devem 
ser integradas para que haja troca de informações e compartilhamento de recursos. É justamente isto que ocorre com a ferramenta MiniTeste e com o aplicativo Multiprova, desenvolvido também no ambiente da ECT/UFRN (Aquino et al., 2014). O Multiprova é um software para geração de avaliações objetivas que permite que variáveis, figuras, gráficos, listas de palavras e outros elementos que compõem uma questão possam variar de forma controlada pelo professor, gerando, a partir de uma matriz de questão, um grande número de questões distintas, porém equivalentes. $\mathrm{O}$ uso dessa ferramenta por diversos professores da ECT/UFRN vem mostrando que ela é eficiente para inibir iniciativas de cola, além de cumprir seu papel principal de ser um sistema de avaliação continuada escalável e de baixo custo operacional.

Para o MiniTeste, a geração de questões individualizadas é proporcionada pela integração com o Multiprova. Dessa forma, o docente possui um único banco de questões que pode ser usado tanto para gerar avaliações mais completas (com várias questões por prova) no Multiprova quanto para usá-las em testes rápidos em sala de aula com o MiniTeste.

Outra funcionalidade importante é a integração com o SIGAA, sistema de gestão de atividades acadêmicas utilizado na UFRN e em dezenas de outras universidades brasileiras. Esse sistema concentra a gestão de disciplinas, notas, turmas virtuais, etc. As informações sobre as turmas do professor são prontamente acessadas pelo usuário logado no MiniTeste, simplificando enormemente o gerenciamento das avaliações desde a sua criação, execução, até a análise das estatísticas.

\subsection{A dinâmica das avaliações com o MiniTeste}

O funcionamento da ferramenta MiniTeste é bem intuitivo. Inicialmente, as questões devem ser elaboradas no Multiprova. A Figura 2 traz o exemplo de uma matriz de prova com uma questão contendo duas subquestões. Assim, se forem solicitadas a geração de 100 provas com base nessa matriz, o Multiprova criará cerca de 50 provas baseado na matriz de questão cujo Id é 2486 e o restante baseado na segunda. No caso em tela, o valor da variável $x$ é sorteado para cada prova que é instanciada. Como foi dito, outros elementos, tais como figuras, listas de palavras e gráficos podem ser inseridos e podem variar de um estudante a outro. Montada a prova, basta o docente exportar a avaliação para posterior importação dentro do MiniTeste.

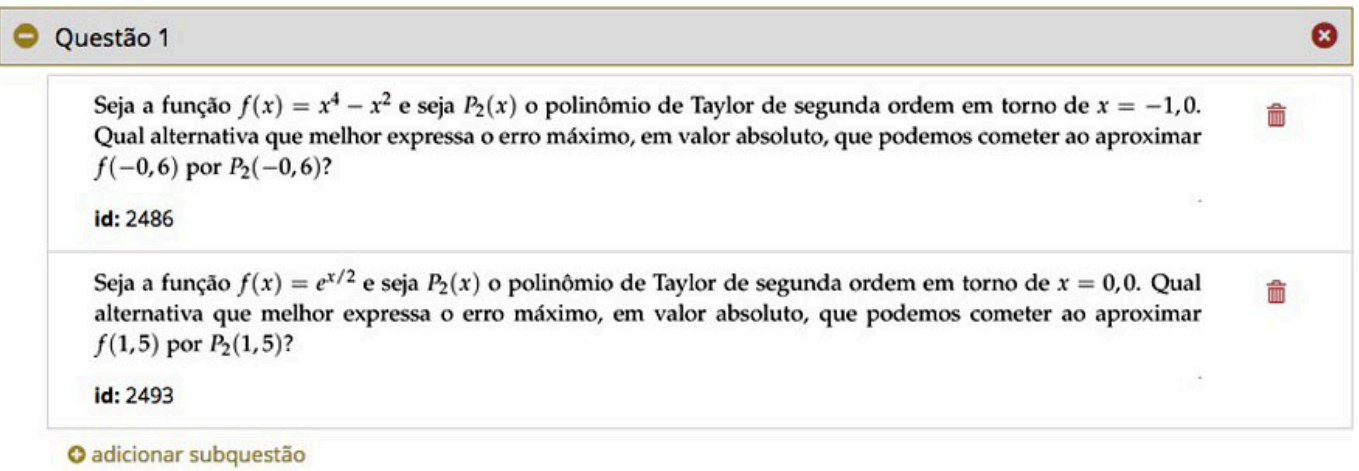

Figura 2 - Elaboração das questões no Multiprova.

Já na plataforma web do MiniTeste, o docente usa as questões advindas do Multiprova para criar um novo miniteste (Figura 3). Destacamos aqui que as turmas do docente no semestre são automaticamente obtidas do SIGAA via webservices. Além de uma pequena descrição, o docente deve escolher a "quantidade de avaliações em papel" 
a serem geradas. Isso porque partimos da premissa de que nem todos os estudantes possuem terminais móveis para responder de forma on-line aos minitestes. Essa quantidade pode ser sondada pelo docente no início do semestre. Outro parâmetro a registrar é se o docente irá permitir que os estudantes saibam se acertaram ou erraram a questão proposta após o envio da resposta. Em algumas situações dentro da metodologia de instrução por pares é interessante que a discussão seja feita sem que os alunos saibam se acertaram ou erraram, por exemplo, se a questão envolve um conceito ou definição.

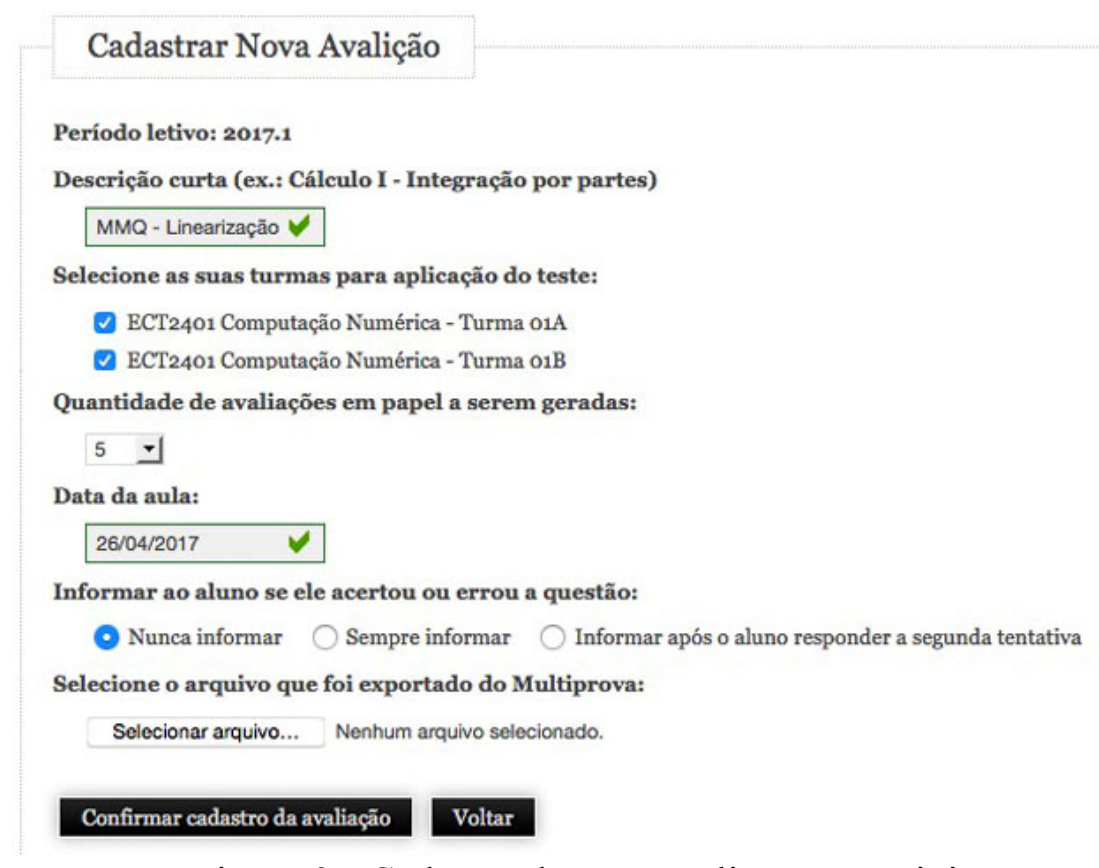

Figura 3 - Cadastro de uma avaliação no MiniTeste.

Uma vez cadastrados, os minitestes são gerenciados a partir da tela mostrada na Figura 4. A partir dessa tela, é possível acessar os relatórios do miniteste em tempo real, iniciar ou terminar a aplicação de um teste e divulgar o resultado para os estudantes (último ícone). No ícone $\Delta$, o docente faz o download de um arquivo PDF contendo os testes na quantidade que ele definiu no momento da criação do miniteste. Um desses testes é mostrado na Figura 5.

$\oplus$ Incluir MiniTeste.

\begin{tabular}{|c|c|c|c|c|}
\hline \multicolumn{3}{|c|}{ MiniTestes por Período: 2017 . } & Ver Avaliaçōes & \\
\hline Data & Turma(s) & Descrição & & Operações \\
\hline $26 / 04$ & ECT2401 (01A,01B,o1C,01D) & MMQ - Linearização & $\Delta$ & $\mathbf{x} 0 \circlearrowleft$ \\
\hline
\end{tabular}

Figura 4 - Gerenciamento de avaliação no MiniTeste.

No início da aplicação do miniteste em sala de aula, os alunos que possuem dispositivos móveis acessam a questão através do endereço http://bct.ect.ufrn.br/movel. Em seguida, o discente pode fazer login na ferramenta usando suas credenciais do SIGAA ou, simplesmente, ele pode inserir a sua matrícula. Se houver uma questão habilitada para responder, ela será apresentada ao aluno conforme mostrado na Figura 6b. Para os que não dispõem de dispositivos móveis, o docente distribui as versões impressas da questão. Do lado esquerdo da Figura 5 é possível notar a presença de um código QR. Esse código de duas dimensões identifica univocamente a questão. Quando 
o discente decide por uma das alternativas, ele usa o dispositivo móvel do colega ou do professor para ler o código QR. Nesse instante, ele é automaticamente redirecionado para uma página web onde é solicitada a sua matrícula (Figura 6a). Ao verificar que o estudante é daquela turma e que o professor já liberou o sistema para aceitar respostas, a mesma questão da avaliação impressa é mostrada ao discente (Figura 6b), que marca a respectiva alternativa. Ao submeter a resposta, o aluno pode saber se acertou ou não a questão e a sua resposta já consta no relatório que o docente pode acessar através do ícone

\author{
UNIVERSIDADE FEDERAL DO RIO GRANDE DO NORTE \\ ECT2401 (01A,01B,01C,01D) - MMQ - Linearização - Per. 2017.1 - (3179)
}

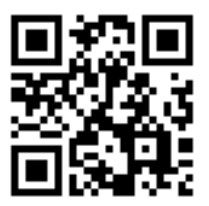

Ajuste os pontos $(4 ; 243)(4.3 ; 316.4)(5.2 ; 1042)$ a uma função do tipo $f(x)=a b^{x}$. Qual a alternativa que melhor representa o valor de $f(5.1)$ ?
(a) 902.1
(b) 906.5
(c) 886.9
(d) 894.7
(e) 881.1
(f) 865.1

Figura 5 - Miniteste impresso. Dependendo do tamanho do enunciado, entre 3 e 5 testes são impressos em uma folha de papel A4.

Apesar de exigir um dispositivo móvel para que a resposta seja efetivamente enviada, a experiência vem mostrando que essa restrição não é um problema. Alguns alunos que possuem aparelhos com configurações simples preferem responder o miniteste impresso e usar o celular do colega para enviar a resposta, já que todo o processo de leitura do código QR e envio da resposta dura apenas alguns segundos.

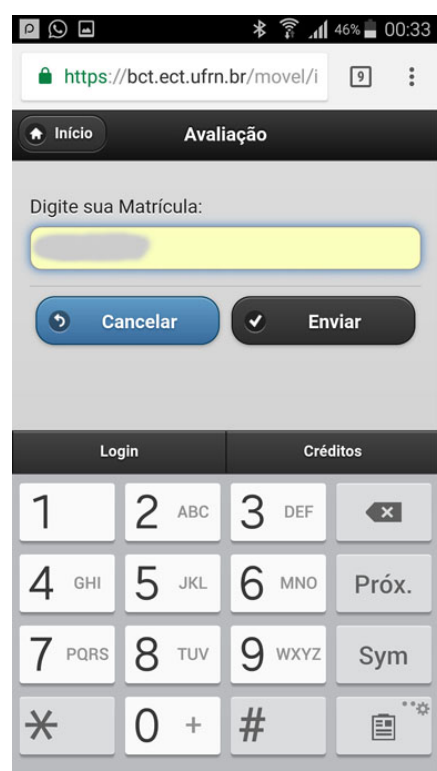

(a)

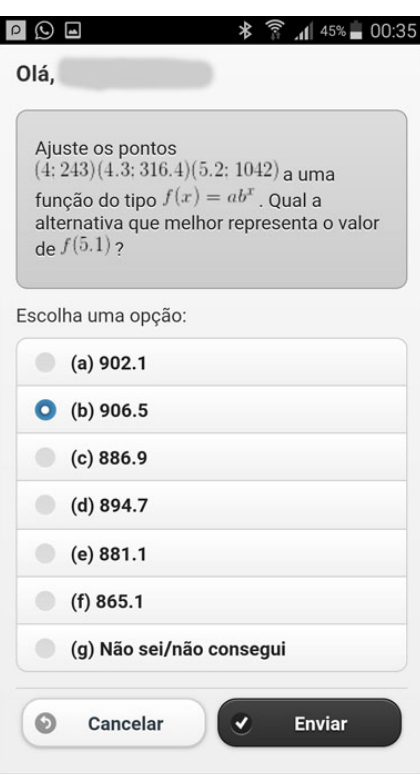

(b)

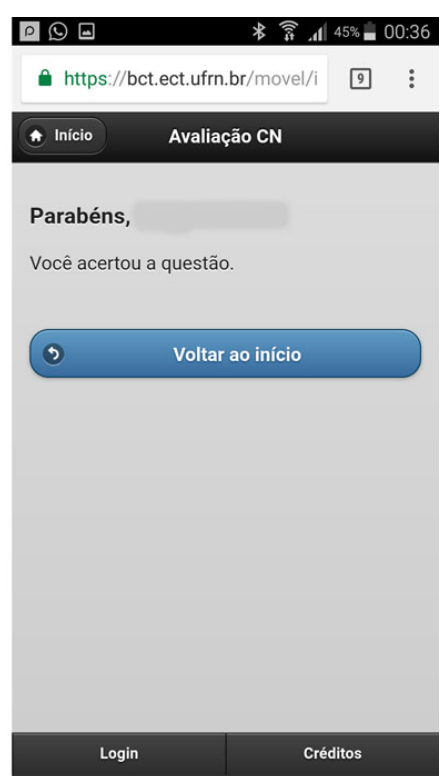

(c)

Figura 6 - As três telas do celular que o discente usa para responder a questão.

À medida em que as respostas são submetidas, o professor acompanha em tempo real o desempenho dos alunos, por meio de gráficos como os da Figura 7. Antes de analisar os dados do relatório é preciso lembrar que na instrução por pares, os alunos que erram a tentativa de responder individualmente têm uma nova oportunidade após uma discussão em pequenos grupos. Assim, esgotado o tempo para resposta individual, 
o professor aciona o ícone $\mathbf{0}$ e o sistema entende que, a partir daquele momento, as respostas devem ser registradas para o que chamamos de segunda tentativa de resposta. Segundo Mazur (1997), a discussão é o momento mais importante da aula e o seu formato vai depender do planejamento prévio de cada docente, levando-se em consideração desde a disponibilidade de monitores e auxiliares de ensino até a disposição e tipo de mobiliário da sala de aula. A partir dos relatos de experiências do uso do MiniTeste, buscaremos adaptar a ferramenta com funcionalidades que auxiliem estudantes e professores, como a formação de grupos segundo critérios definidos pelos docentes.

Analisando-se um desses relatórios, vê-se que na "primeira tentativa" apenas 24 alunos $(31,6 \%)$ acertaram a questão, enquanto 52 alunos $(68,4 \%)$ não conseguiram responder de forma individual. Após a discussão em grupo, dos que erraram ou não fizeram a questão, 62,3\% conseguiram acertar. Ao final do processo, $75 \%$ da turma obteve êxito ao responder a questão.

Caso haja um desempenho insatisfatório da turma, o professor terá essa informação rapidamente e poderá, usando suas estratégias pedagógicas, atuar para induzir o entendimento coletivo. Pela praticidade dos minitestes, o domínio do assunto pode ser novamente verificado por uma segunda avaliação.

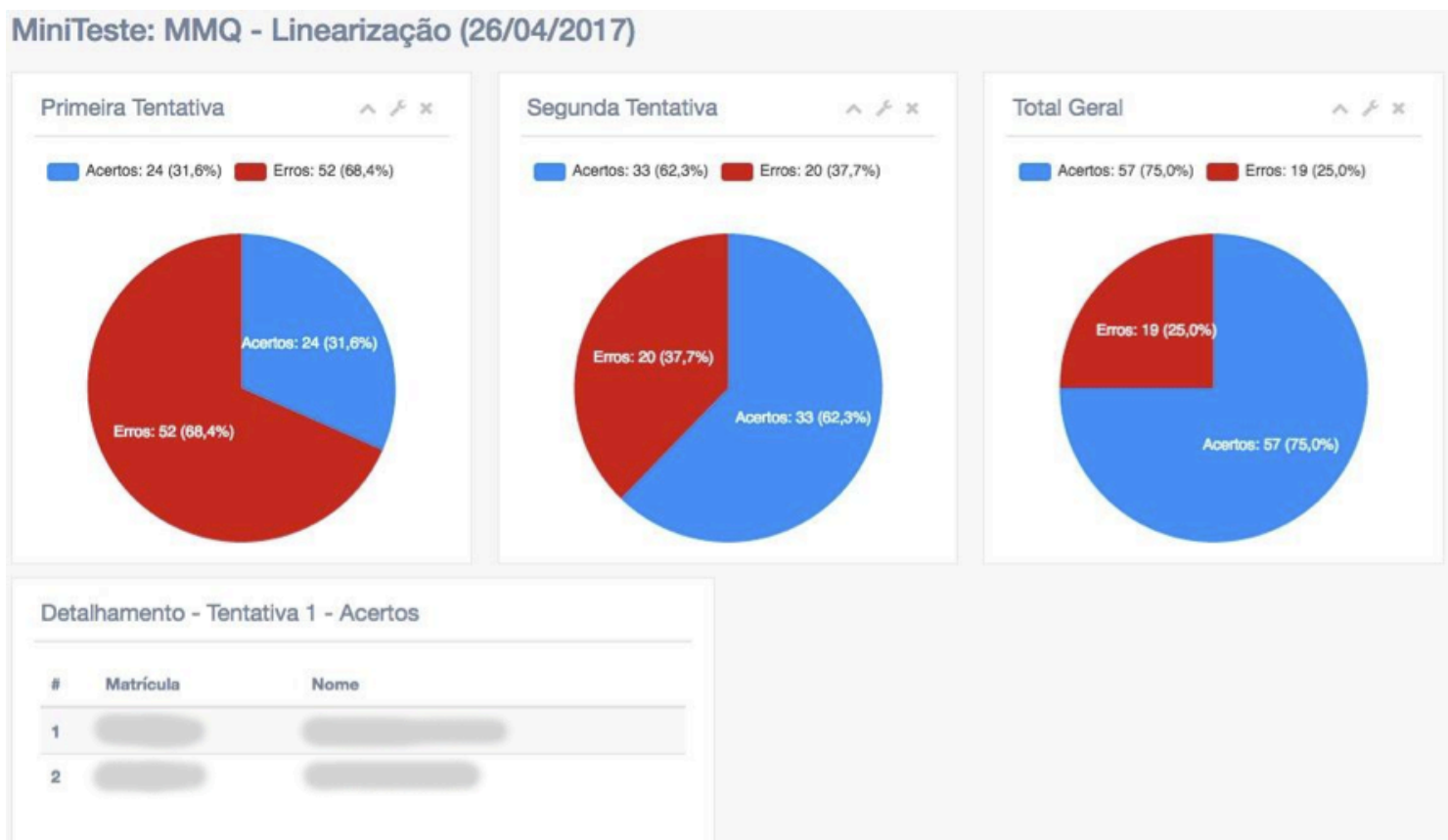

Figura 7 - Relatório em tempo real emitido pelo MiniTeste.

Estatísticas mais detalhadas com informações sobre o desempenho acumulado de cada estudante ou de uma turma estão sendo implementadas.

\section{Outras possíveis aplicações}

A ferramenta MiniTeste foi desenvolvida considerando um contexto específico, que era o suporte às metodologias ativas empregadas pelos docentes da ECT/UFRN, em especial, a instrução por pares. Além desse horizonte, vislumbramos aplicações em diversos cenários, mesmo na adoção de outras metodologias ativas, como é o caso do aprendizado baseado em equipes (Bollela, 2014). Nela, durante a fase de aplicação dos conceitos nos encontros presenciais, os estudantes são convidados a responder questões 
de múltipla escolha individual e coletivamente. A ferramenta também pode ser utilizada nos processos de avaliação continuada, com testes surpresa durante a aula e sem grandes preparativos, com resultados conhecidos de forma imediata. Também pode ser usada fora do horário da aula presencial através da disponibilização, por parte do professor, de questões-chave a serem resolvidas pelos estudantes. Essa estratégia possibilita identificar o nível de entendimento dos alunos sobre um determinado conteúdo essencial a novos desenvolvimentos.

Atualmente, o MiniTeste integra um conjunto de ferramentas web desenvolvidas para dar suporte aos alunos e docentes do curso de Ciências e Tecnologia da UFRN e está disponível no portal http://www.bct.ect.ufrn.br. Uma vez que o portal está integrado ao SIGAA, qualquer um dos mais de 2000 docentes da UFRN pode ter acesso ao sistema. Uma versão do MiniTeste para professores e estudantes de fora da UFRN está sendo desenvolvida. Dentre os desafios dessa extensão está a adaptação das funcionalidades que dependem da integração com o SIGAA e com o Multiprova.

\section{Conclusões}

As metodologias ativas procuram fazer com que os estudantes exerçam o seu protagonismo no processo de ensino-aprendizagem. As novas tecnologias têm muito o que contribuir com esse processo complexo. Em particular, as avaliações devem ser mais frequentes para trazer informações aos estudantes e ao professor, indutor do aprendizado. Para estar em sintonia com a necessidade da turma, é essencial que as avaliações sejam de baixo custo operacional e não sejam estruturas rígidas, prédefinidas, mas que tenham uma dinâmica flexível, podendo ser adaptadas durante sua aplicação. $\mathrm{O}$ uso de testes rápidos, como os que são criados com a ferramenta MiniTeste, possibilita que o docente prepare diversos cenários para o momento do encontro presencial, de forma que a aula possa ser adaptada às necessidades da turma, em tempo real.

\section{Referências}

AQUINO JUNIOR, G. S.; SILVA, D. R. C.; BESSA, A. MARTINS, A. M. Integração da ferramenta Multiprova ao sistema integrado de gestão de atividades acadêmicas. RENOTE - Revista Novas Tecnologias na Educação, v. 12, n. 2, 2014.

BOllelA, V. R.; SENGER, M. H.; TOURINHO, F. S. V.; AMARAL, E. Aprendizagem baseada em equipes: da teoria à prática. Medicina (Ribeirão Preto), v. 47, n.3, p. 293-300, 2014.

GERAB, F.; TRENTIN, P. H. A construção de mapas conceituais: uma metodologia ativa de aprendizagem para o cálculo diferencial e integral no curso de engenharia. In: CONGRESSO BRASILEIRO DE EDUCAÇÃO EM ENGENHARIA, 43., 2015. São José dos Campos. Anais. São José dos Campos, Associação Brasileira de Educação em Engenharia, 2015.

JOHNSON, A. H.; PERCIVAL, F. A schematic representation of the conclusions drawn. Attention breaks in lectures. Education in Chemistry, v. 13, p. 49-50, 1976.

MAZUR, Eric. Peer instruction. A user's manual. New Jersey: Prentice Hall Series in Education Innovation. Prentice Hall, 1997. 
MÜLLER, M. G. Metodologias interativas de ensino na formação de professores de física: um estudo de caso com o peer instruction. Porto Alegre: IF/UFRGS, 2013, 226p. Dissertação de Mestrado.

POH, M. Z.; SWENSON N. C.; PICARD, R. W. Picard. A wearable sensor for unobtrusive, long-term assessment of electrodermal activity. IEEE Transactions on Biomedical Engineering, v. 57, n. 5, p. 1243-1252, 2010.

SOUZA, S. O. Aprendizagem baseada em problemas (PBL - Problem-Based Learning): estratégia para o ensino e aprendizagem de algoritmos e conteúdos computacionais. Presidente Prudente: FCT/UNESP, 2011, 251p. Dissertação de Mestrado.

UNIVERSIDADE FEDERAL DO RIO GRANDE DO NORTE. Observatório da vida do estudante universitário da UFRN. Disponível em: $<$ http://ww.comperve.ufrn.br/conteudo/observatorio>. Acesso em: 19 dez. 2016. 